\title{
Technological Innovations Utilization Framework: The Complementary Powers of UTAUT, HOT-Fit Framework and; DeLone and McLean IS Model
}

\author{
Edwin Omol ${ }^{1, *}$, Collins Ondiek ${ }^{2}$ \\ ${ }^{1}$ School of Computing and Information Technology, Kenya Highlands University,Kericho,Kenya \\ ${ }^{2}$ School of Computing and Information Management, KCA University, Kenya. \\ *Corresponding Author: omoledwin@gmail.com \\ DOI: 10.29322/IJSRP.11.09.2021.p11720 \\ http://dx.doi.org/10.29322/IJSRP.11.09.2021.p11720
}

\begin{abstract}
:
Theories and models have been developed to explore the diffusion, adoption or acceptance and utilization of Technological Innovations. The literature traversed fortifies the successful utilization of technological innovations on a number of contexts which are identified in three broad zones as; technological, organizational and human context. It's however disquieting that none of the theories and models traversed in the literature distinctively underpins these contexts conclusively. To appreciate the above contexts, this study settles on the underneath twin models and solitary framework as the combination is believed to exhaustively wrestle the phenomena. Disregarding the concept of parsimony and embracing a post-positivist approach to theory development affixing the foundation on an exploratory sequential method design utilizing existing literature especially on adoption, usage, acceptance, implementation and utilization of technology, the study thus develops a multi-dimensional theoretical framework, derived from DeLone and McLean model, UTAUT and HOT-fit Framework.
\end{abstract}

Keywords: DeLone and McLean model, HOT-fit Framework, Technological innovations utilization and UTAUT

\subsection{Introduction}

Technological Innovations Utilization is the behaviour of using technology to accomplish some tasks [1]. Utilization in this study is anchored on three broad areas as; (1) people (Behavioral Intentions (BI); Performance Expectancy (PE), Effort Expectancy (EE) and Social Influence (SI)), (2) process (Organization; internal environment and structure) and (3) Technological (System quality, Information quality and Service Quality) factors. On trying to shade some light on factors affecting the utilization and adoption of technology in 
Education, Mustapha et al., [2] identified teachers', organizational and technological factors to influence technology utilization in education. Similarly, Tripathi and Pandit, [3] contribution towards understanding the factors that influence the adoption of IoT in businesses isolated technical, personal and organizational factors as domicile.

In the information systems studies, the fit between the people, environment, organization, and technology itself, has been studied by many researchers [4]. Information systems are implemented in social system such as organization in which different kind of people and environments interact with each other [5]. Various fit concepts have been studied and developed by various studies and have become a reference for research in the field of information systems. One of the fit models that is quite popular in information systems research is Human Technology Organization Fit (HOT Fit) developed by Yusof et al., [6]. Moreover, Stylianides et al., [7] acknowledged Human, Technology and Organization as the main areas within which they affixed their evaluation framework for hospitals utilizing Integrated Health Information System (IHIS).

In the HOT Fit model, human (Behavioral Intentions), organization (processes), and technology is an important elements of the information system especially in healthcare sector [8]. Lack of the fit between those three elements contributes to the utilization failure of Health information systems [6]. In other words, the fit between the three elements is a key to the successful utilization of the information systems [4]. In the use of information systems, the higher the fit between users, technology, and organization is, the higher the impact on the user acceptance of information systems is [5]. The alignment between organization, technology, and human components become an important point in the application of information technology which affects investment in the information technology [9].

Despite this agreement in the literature that successful utilization of technological innovations spin around human, organization and technological factors, the selected two models and a framework cannot be distinctively relied on to underpin the factors as each has its own deficiencies as summarized in Table 1. below.

Table 1: Summary of the models/Framework and their limitations

\begin{tabular}{|l|l|l|l|}
\hline Models/Framework & Author & Constructs & Limitations \\
\hline $\begin{array}{l}\text { DeLone and McLean IS } \\
\text { model }\end{array}$ & $\begin{array}{l}\text { DeLone and } \\
\text { McLean, 2003 }\end{array}$ & $\begin{array}{l}\checkmark \text { System quality } \\
\checkmark \text { Information quality } \\
\checkmark \text { Service quality }\end{array}$ & $\begin{array}{l}\checkmark \\
\text { Lacks a stronger and sound } \\
\text { theoretical background for } \\
\text { predicting behavioral intention } \\
\text { (BI) }\end{array}$ \\
& $\begin{array}{l}\checkmark \\
\text { The relationship between } \\
\text { intention to use and actual use is } \\
\text { "notoriously difficult to }\end{array}$ \\
\hline
\end{tabular}




\begin{tabular}{|c|c|c|c|}
\hline & & & $\begin{array}{ll} & \text { measure" } \\
\checkmark & \text { Does not address organization } \\
\text { and social contexts }\end{array}$ \\
\hline UTAUT & $\begin{array}{l}\text { Venkatesh et } \\
\text { al.,(2003) }\end{array}$ & $\begin{array}{ll}\checkmark & \text { Performance } \\
& \text { Expectance (PE) } \\
\checkmark & \text { Effort Expectance } \\
& \text { (EE) } \\
\checkmark & \text { Social Influence } \\
& (\mathrm{SI})\end{array}$ & $\begin{array}{ll}\checkmark & \text { UTAUT is designated for } \\
\text { mandatory use } \\
\checkmark & \text { Silent on technological and } \\
\text { organization contexts }\end{array}$ \\
\hline HOT-Fit Framework & Yusof et al., [6] & $\begin{array}{ll}\checkmark & \text { Human } \\
\checkmark & \text { Organization } \\
\checkmark & \text { Technology }\end{array}$ & $\begin{array}{ll}\checkmark & \text { Lacks quantitative empirical } \\
& \text { validation } \\
\checkmark & \text { Lacks a stronger and sound } \\
\text { theoretical background for } \\
\text { predicting behavioral intention } \\
\text { (BI) }\end{array}$ \\
\hline
\end{tabular}

Source: Own Conceptualization (2021)

\subsection{Materials and Methods}

This study embraced a post-positivist approach to theory development affixing its foundation on an exploratory sequential method design utilizing existing literature to build the framework but to further shade more light on the phenomena, epistemological stances of the study is also reconnoitered. The study focused only on the literatures with the keywords "Adoption, Acceptance, Implementation, Usage and Utilization of Technology/Information Systems"

\subsection{Results}

According to Mardiana et al., [10], DeLone and McLean model has a number of shortcomings. In their quest to address the inadequacies, they suggested the introduction of TAM and UTAUT to provide strong theoretical background to intention to use construct but shockingly oversaw the inclusion of culture in evaluating Information Systems utilization. In their confession, additional research is needed to discover the possibility of the influence of culture toward IS success, since numerous literature is overwhelmingly giving the proofs for cultural involvement on the IS's users that in turn could affect IS itself [10]. It's therefore against this background that this study calls the attention of UTAUT model and HOT-FIT framework to reinforce other additional success factors of technological innovation utilization.

The realization of Technological innovation according to Yusof et al., [11] requires rigorous evaluation that addresses technology, human and organization issues. In 2006, Yusof et al. developed a framework that combined the concept of the DeLone and McLean model and the IT- Organizational Fit Model. According to Yusof et al. [6], the framework for evaluating these innovations shall consider human and organization. Besides 
that, the health information system also needs to be supported and equipped with the technological innovations. Organization in healthcare sector must have an ability to prepare workers or staff to adapt with new technology or changes that may occur. The HOT-Fit has three aspects and different dimensions in every aspect. In technology aspect, there are three dimensions: (1) system quality; (2) information quality; (3) service quality. In human aspect, there are two dimensions: (1) system use; and (2) user satisfaction. In organization aspect, there are two dimensions: (1) structure; and (2) environment. Nonetheless just like this framework had a number of weaknesses since it wasn't tested by any quantitative method, only described its dimensions and variables while the statement of research instrument was missing. Besides, the framework also oversaw theoretical foundation behind system use and user satisfaction which this study seeks to abridge using UTAUT as shown in Figure 1.

From the two models and a framework, this study draws its theoretical foundation as exhibited in Figure 1. The resultant framework would be viewed as an extension of DeLone and McLean IS model with an inclusion of organization context, social influence besides stronger and sound theoretical background for predicting behavioral intention (BI) which is missing or an extension of HOT-Fit Framework with annexation of solider and thorough theoretical background for predicting behavioral intention (BI). The inclusion of social influence as stipulated in UTAUT is in response to the call by Mardiana et al., [10] to discover the possibility of the influence of culture toward IS success, since numerous literature is overwhelmingly giving the proofs for cultural involvement on the IS's users that in turn could affect IS itself [10]. The context diagram above for the technological innovations summarizes the system's (innovation) organization, social, user and Technological availability factors and shows their interaction to yield technological innovations' benefits and utilization.

Figure 1: Unified Theoretical Framework

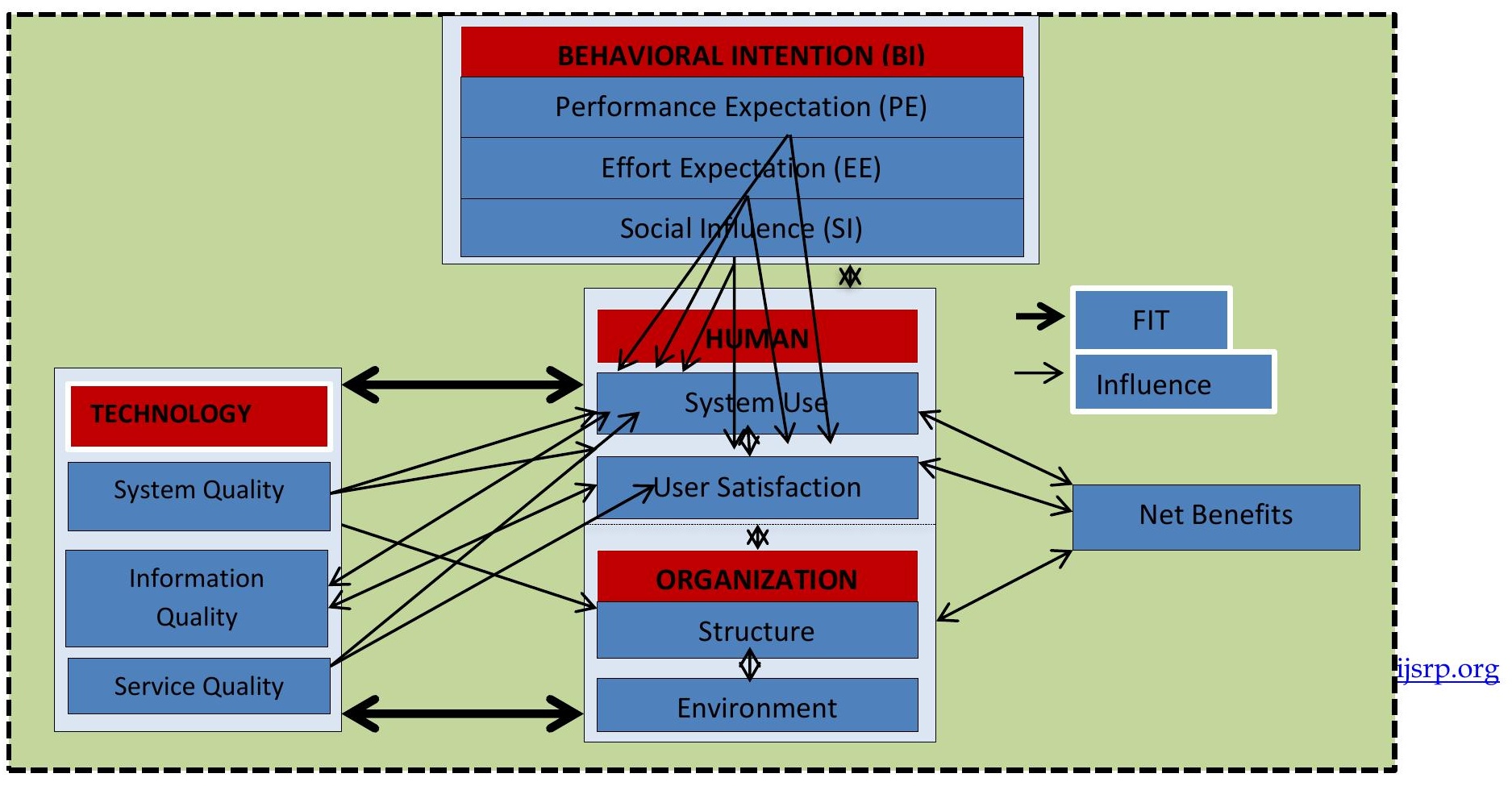


Source: Own Conceptualization (2021)

It highlights the elements that should be present and how they interact. Classification framework in table 2 gives the conceptual definitions of the constructs of the study

Table 2: Classification framework and their conceptual definitions

\begin{tabular}{|c|c|c|c|}
\hline Context & & Factor within the context & Explanation \\
\hline \multirow[t]{3}{*}{$\begin{array}{l}\text { Behavioral } \\
\text { (BI) }\end{array}$} & \multirow[t]{3}{*}{ Intention } & Performance Expectancy(PE) & $\begin{array}{l}\checkmark \text { The degree to which an individual believes } \\
\text { that using the system will help him or her to } \\
\text { achieve increases in job performance } \\
\text { (Venkatesh et al., 2003) }\end{array}$ \\
\hline & & Effort Expectancy(EE) & $\begin{array}{l}\checkmark \text { The degree of ease associated with the use of } \\
\text { the system (Venkatesh et al., 2003). }\end{array}$ \\
\hline & & Social Influence (SI) & $\begin{array}{l}\checkmark \text { The degree to which an individual perceives } \\
\text { that important others believe he or she should } \\
\text { use the new system (Venkatesh et al., 2003). }\end{array}$ \\
\hline \multirow{3}{*}{\multicolumn{2}{|c|}{ Technology }} & System Quality & $\begin{array}{l}\checkmark \text { Desired characteristics of the information } \\
\text { system }\end{array}$ \\
\hline & & Information Quality & $\begin{array}{l}\checkmark \text { Desired characteristics of the information } \\
\text { systems output. }\end{array}$ \\
\hline & & Service Quality & $\begin{array}{l}\checkmark \text { The quality of support rendered by the } \\
\text { information system's developer }\end{array}$ \\
\hline \multirow{2}{*}{\multicolumn{2}{|c|}{ Organization }} & Structure & $\begin{array}{l}\checkmark \text { Organization's sense of identity, its goal or } \\
\text { core values, its primary ways of working and } \\
\text { a set of shared assumptions (Schein, 1992). }\end{array}$ \\
\hline & & Environment & $\begin{array}{l}\checkmark \text { The setting in which the organization } \\
\text { conducts business, and influenced by the } \\
\text { industry itself, its competitors, the } \\
\text { organization's ability to access resources } \\
\text { supplied by others, and interactions with the } \\
\text { government }\end{array}$ \\
\hline \multirow{2}{*}{\multicolumn{2}{|c|}{ Human }} & System use & $\begin{array}{l}\checkmark \text { The degree and manner in which user utilize } \\
\text { the capabilities of an information system }\end{array}$ \\
\hline & & User satisfaction & $\checkmark$ Users' level of satisfaction \\
\hline \multirow{2}{*}{\multicolumn{2}{|c|}{ Net Benefits }} & Measured & $\begin{array}{l}\checkmark \text { Is the use of IS in the primary process which } \\
\text { in turn results into effects that ensure the core } \\
\text { focus of the service delivery is achieved }\end{array}$ \\
\hline & & Anticipated & $\begin{array}{l}\checkmark \text { Lessening the pressure on the healthcare } \\
\text { facilities and professionals } \\
\checkmark \quad \text { The organization and the management of, and } \\
\text { reporting of service delivery. }\end{array}$ \\
\hline
\end{tabular}




\begin{tabular}{|l|l|l|}
\hline & & $\begin{array}{l}\checkmark \\
\text { Computerizing processes, affording the } \\
\text { provider more time and opportunities to do } \\
\text { what their profession demands. }\end{array}$ \\
\hline
\end{tabular}

Source: Own Conceptualization (2021)

\subsection{The Formulated framework}

Certain of the intricacy of Technology arena, the study illuminate the multifaceted interaction between the various stakeholders and issues which are pertinent in the evaluation process of technological innovations' utilization by exhausting the muscles of DeLone and McLean model, UTAUT and HOT-fit Framework. These are conceptualized in Figure 2, which shows the fundamental factors determining the successful utilization of technological innovations, how they relate to each other and the interaction between the research variables. The framework assumes factors as captured in figure 2, as interacting unidirectional to influence the suitability and utilization of technological innovations. The successful utilization of an innovation is thus envisioned as being impacted on by different factors as indicated in Figure 2.

This study borrows from Technology, Individual, Process-Fit (TIPFit) model built on the context that the predictive variables for FIT and utilization of mHealth as technological innovation spin around people, process and technology. The study's point of departure however is the formulation of these variables. The variables are not anchored on any known theoretical background hence this study redesigns TIP-Fit underpinning it on DeLone \& McLean IS success Model, UTAUT and HOT-Fit to envisage the potential Fit and Utilization of technological innovations as presented in Figure 2.

Figure 2: Study's Framework

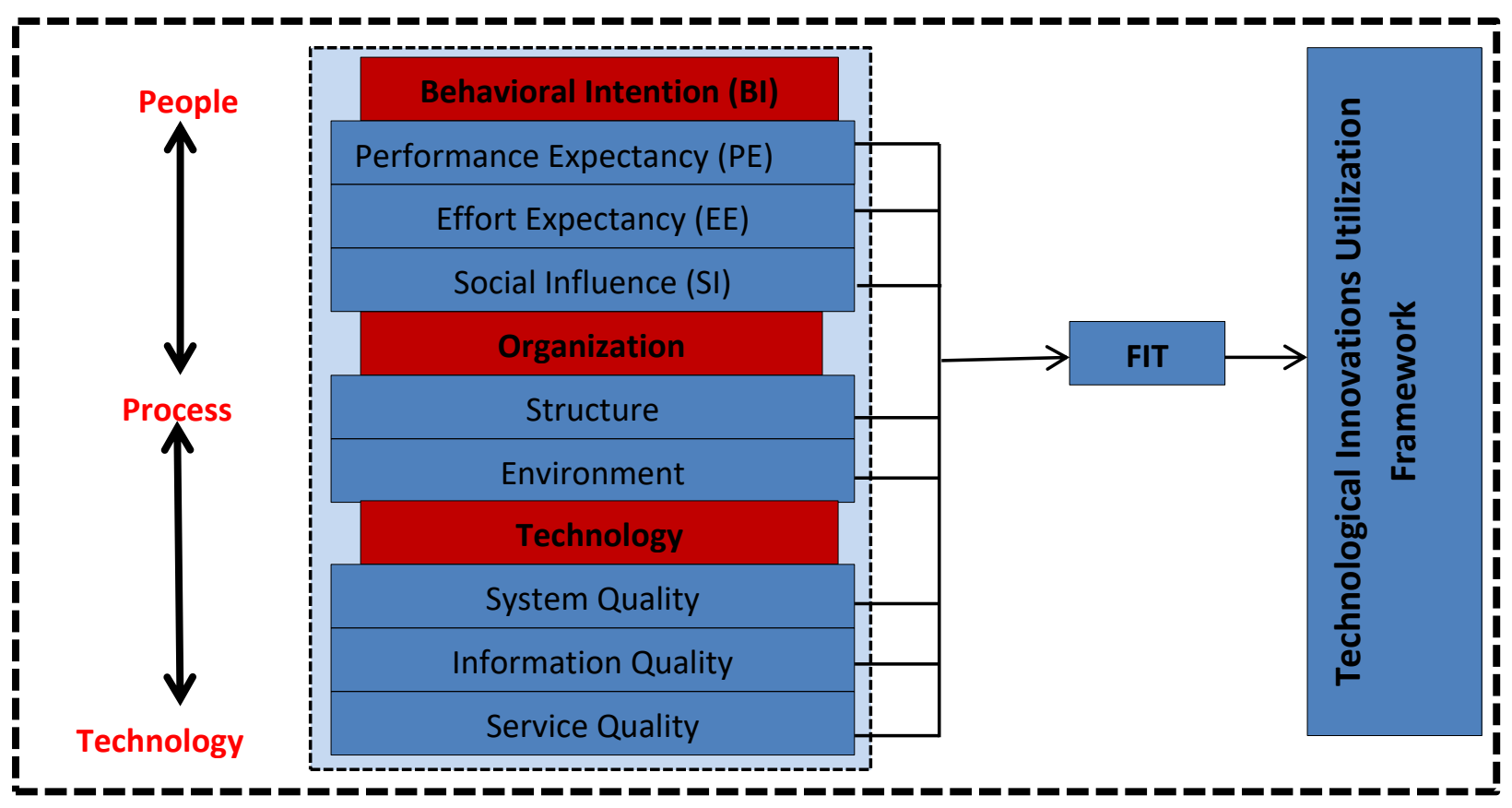

Source: Mburu \& Oboko [1] \& modified to suite the research

This publication is licensed under Creative Commons Attribution CC BY. 


\subsection{Discussion}

Theories and models have been developed to explore the diffusion, adoption or acceptance and utilization of technological innovations [16]. In broader perspective, this study comes to an agreement with Mburu \& Oboko [1] that contextually, diffusion, adoption or acceptance and utilization of technological innovations researches have always revolve around people, process and technology. The reviewed studies for example Davis \& Venkatesh, [13], Bhattacherjee \& Premkumar, [12] and Mburu \& Oboko [1] on technology adoption have demonstrated how to predict utilization based on theoretical knowledge of causal connections. To predict acceptance and use of system/technology/innovation Davis \& Venkatesh, [13] used Perceived Usefulness, Bhattacherjee \& Premkumar, (2004) used the same approach to provide empirical evidence on predictive approach to user acceptance a leaf that was borrowed by Mburu \& Oboko [1] in predicting acceptance and use of mHealth interventions in low-resource settings. The acceptance and use herein is based on the Behavioral Intentions (BI) of individual's perceptions on innovations hence the people's contextualization in this research.

To better understand Behavioral Intentions (BI), this study trusted UTAUT which conceptually enhanced TAM [16] with capabilities of measuring Social Influence (SI) on acceptance and use of an innovation. The constructs of measure on Behavioral Intentions (BI) is based on a result of the meta-analysis study of studies by Mardiana et al., [10] which resolved that the three variables (PE, EE, and SI) are good predictors for BI, the position held by Taiwo and Downe, [17] and Dwivedi et al., [18] who found the three to have strong significant support for BI. And further reinforced by Hongkong study using a modified UTAUT model, where Chan et al., [20] stated that PE and EE are among the important variables for evaluating system in mandatory environment.

The second context as borrowed from Mburu \& Oboko [1] TIP-Fit model is Process. A number of researches have argued that application or adoption of technology in a setting is a process [14] which in the view of Omol et al., [15] incorporates a number of factors; material artifacts, ways of working and thinking, models, tools, machines, papers and files and all these this study views as the prerogative of the organization factors in the successful adoption, application or use of an Innovation. Technology should not be reduced to delivery, application or immediate use but also understood as both cause and consequences longer-term processes of change [16].

Omol et al., [15] views people, process and technology as co-constitutive; that is, their ability to perform actions (in this case consultative based on some process) and to produce effects (for example diagnosis); their collective agency- is distributed between the various parts and performed each time things happen [16]. Technological artifacts are designed for particular purposes for example to reduce prescribing errors, but also embody certain interest for example of doctors, technologists, managers or patients. As a result, technology can 
be said to be designed to support people in organization governed by some processes in the task they are expected to perform. Technology therefore let managers and other workers redesign their tasks following some processes hence the process and technology contexts in the conceptual framework.

In the study's quest to appreciate process and technological context especially their contribution towards the fitness and utilization of IoHT innovations, DeLone \& McLean IS success Model, and HOT-Fit framework are arrayed. Subsequent decision regarding the use of a systems according DeLone and McLean, [21] should be based on the use of tested and proven measures, of IS success, from existing research and indeed the most popular and most validated measure is the DeLone and McLean IS success model (D\&M model) [22]. Based on some meta-analysis studies of DeLone-Mclean model [23], it is revealed that some relationships in the construct are not significant [10]. As such, the construct validity is questionable and might lower the predicting power. The integration of TAM and UTAUT into DeLone-McLean model proposed to provide proper antecedents for intention to use since TAMs has a stronger and sound theoretical background for predicting behavioral intention (BI). But even with the inclusion of TAM and UTAUT into DeLone-McLean model, this study takes a position that successful adoption, application and utilization of technology goes beyond individual and technological factors to even include organizational factors like the environment and structure hence the introduction of HOT-Fit Framework by Yusof et al., [6].

HOT-Fit framework reasons that success in managing the deployment of information technology in the organization depends on the balance in the following six factors: (1) external environment; (2) organization strategy; (3) individuals and roles; (4) organization structure; (5) technology and; (6) management processes [6] in order to attain long term benefits of technological innovations [16]. The engagements shall be supported by organization and technology. This underlines three important factors in successful utilization of information system, which are human, organization, and technology. To evaluate how these three aspects are interrelated in the utilization of information system, the Human, Organization, and Technology-Fit (HOT-Fit) framework by Yusof et al. [6] fits this purpose. While the discussion upon a framework to evaluate the application of information system is limited, this framework presents a model to help understand the interrelated aspects of human, organization, and technology [24].

\subsection{Conclusion}

Due to gaps identified in the reviewed models and theories especially the aforementioned, we derived a structural model for predicting utilization of technological innovations. According to the invocations of this study, antagonizing the two models and the HOT-framework gives a clearer precipitate for the successful utilization of Technological innovations since the three major domains of human, organization, and technology 
are captured. This study therefore builds an amalgamated approach to predict acceptance and use of technological Innovations. This framework can be applied using qualitative, quantitative and a combination of both approaches.

\section{REFERENCE}

[1] Mburu, S. \& Oboko, R. (2018). A model for predicting utilization of mHealth interventions in low-resource settings: case of maternal and newborn care in Kenya. BMC Med Inform Decis Mak 18, 67 (2018). https://doi.org/10.1186/s12911-018-0649-z

[2] Mustapha, A., Mohammed, A., Egigogo, A. R., Kutiriko, A. A. \& Dokoro, A. H., (2020). Factors Affecting the Utilization and Adoption of Technology in Education. intechopen. DOI: http://dx.doi.org/10.5772/intechopen.85712

[3] Tripathi and Pandit January 2019. Theoretical Economics Letters 09(07):2606-2625. Analysis of Factors Influencing Adoption of Internet of Things: A System Dynamics Approach DOI: 10.4236/tel.2019.97164

[4] Muslimin, I., Hadi, S. P., \& Nugroho, E. (2017). An Evaluation Model Using Perceived User Technology Organization Fit Variable for Evaluating the Success of Information Systems. Scientific Journal of Informatics, 4(2), 86-94. doi: 10.15294/sji.v4i2.12012

[5] Mohamadali N. A. K. S. \& Garibaldi J. M. (2012). “Understanding and Addressing the 'Fit' between User, Technology and Organization in Evaluating user Acceptance of Healthcare Technology." in International Conference on Health Informatics. 119-124.

[6] Yusof M. M., Paul R. J., and Stergioulas L. K..( 2006). “Towards a Framework for Health Information Systems Evaluation.” in Hawaii International Conference on System Sceinces. Vol. 39. 1-10.

[7] Stylianides, A., Mantas, J., Roupa, Z., \& Yamasaki, E. (2018). Development of an Evaluation Framework for Health Information Systems (DIPSA). Acta Informatica Medica, 26(4), 230. doi: 10.5455/aim.2018.26.230234

[8] Yusof M. M., Kuljis J., Papazafeiropoulou A., \& Stergioulas L. K.. (2008). “An evaluation framework for Health Information Systems: human, organization and technology-fit factors (HOT-fit).” International Journal of Health Informatics. Vol. 77(6): 386-398.

[9] Willcocks, L. (1994). Managing technology evaluation-techniques and processes, in: R.D. Galliers, B.S.H. Baker (Eds.), Strategic Information Management: Challenges and Strategies in Managing Information Systems. [10] Mardiana, S., Tjakraatmadja, H. \& Aprianingsih, A. (2015). DeLone-McLean IS Success Model Revisited: The Separation of Intention to Use - Use and the Integration of Technology Acceptance Models. International Journal of Economics and Financial Issues, 2015, 5(Special Issue) 172-182. 2nd AFAP 
International Conference On Entrepreneurship And Business Management (AICEBM 2015), 10-11 January 2015, Universiti Teknologi Malaysia, Kuala Lumpur, Malaysia.

[11] Yusof M.M., Kuljis J., Papazafeiropoulou A., Stergioulas L.K., (2008) .An evaluation framework for health information systems: human, organization and technology-fit factors (HOT-fit). Int J Med Inf 77(6):386398

[12] Bhattacherjee A. \& Premkumar G. (2004). Understanding changes in belief and attitude toward information technology usage: a theoretical model and longitudinal test. MIS Q. 2004;28(2):229-54.

[13] Davis, F. D. \& Venkatesh, V. (2004).Toward pre-prototype user acceptance testing of new information systems: implications for software Project Management. IEEE Trans on Engineering Management. 2004;51:31-46.

[14] Wauyo, F, Omol, E \& Okumu, J., (2017): Effectiveness of Business Intelligence Technology Absorptive Capacity and Innovation Competency of University Staff, Case of Uganda Christian University Mbale Campus. European Journal of Technology (EJT). DOI: $\underline{10.47672 / e j t .223}$

[15] E Omol, S Abeka, F Wauyo (2017): Factors Influencing Acceptance of Mobile money Applications in Enterprise Management: A Case Study of Micro and Small Enterprise Owners in Kisumu Central Business District, Kenya. International Journal of Advanced Research in Computer and Communication Engineering ISO 3297:2007 Certified Vol. 6, Issue 1, and January 2017.

[16] Omol, E et al., (2016). Mobile Money Payment Acceptance Model in Enterprise Management: A Case Study of MSE's in Kisumu City, Kenya. Mara Research Journal of Information Science \& Technology Vol.1, No,2, August 2016, Pages 1-12

[17] Taiwo, A.A., Downe, A.G. (2013), The theory of user acceptance and use of technology (UTAUT): A meta-analytic review of empirical findings. Journal of Theoretical and Applied Information Technology, 49(1), $1-11$.

[18] Dwivedi, Y.K., Rana, N.P., Chen, H., Williams, M.D. (2011), A meta- analysis of the unified theory of acceptance and use of technology (UTAUT). In: Nüttgens, M., Gadatsch, A., Kautz, K., Schirmer, I., Blinn, N., editors. Governance and Sustainability in Information Systems. Managing the Transfer and Diffusion of IT. Berlin, Heidelberg: Springer; p155-170.

[20] Chan, F.K.Y., Thong, J.Y.L., Venkatesh, V., Brown, S.A., Hu, P.J., Tam, K.Y. (2010),Modeling Citizen Satisfaction with mandatory adoption of an e-government technology. Journal of the Association for Information Systems, 11(10), 519-549.

[21] DeLone, W.H., McLean, E.R. (1992), Information systems success: The quest for the dependent variable. Information Systems Research, 3(1), 60-95.

[22] DeLone, W.H., Mclean, E.R. (2002), Information systems success revisited. In Proceedings of the $35^{\text {th }}$ 
Hawaii International Conference on System Sciences. p1-11.

[23] DeLone, W.H., McLean, E.R. (2003), The DeLone and McLean model of information systems success: A ten-year update. Journal of Management Information Systems, 19(4), 9-30.

[24] Erlirianto, L. M., Ali, A. H. N., Herdiyanti, A., (2015). The Implementation Of the Human, Organization, and Technology-fit (hot-fit) Framework To Evaluate the Electronic Health Record (emr) System in a Hospital. https://www.sciencedirect.com/science/article/pii/S1877050915036273 